\title{
Combination of nitrous oxide and lidocaine to prevent withdrawal after rocuronium in children
}

\author{
Hyun-Jeong Kwak ${ }^{1}$, Yun Jeong Chae ${ }^{2}$, Sook Young Lee ${ }^{2}$, Young Jun Kim², and Jong-Yeop Kim² \\ Department of Anesthesiology and Pain Medicine, ${ }^{1}$ Gil Medical Center, Gachon University of Medicine and Science, Incheon, ${ }^{2}$ Ajou \\ University School of Medicine, Suwon, Korea
}

Background: Pain at the site of rocuronium injection is a common side-effect in pediatric patients. This prospective, randomized, double-blind study evaluated the efficacy of a combination of nitrous oxide and lidocaine pretreatment on withdrawal response during rocuronium injection in children.

Methods: Sixty six pediatric patients, ages 5 to 12 years, were randomly assigned to two groups. The oxygen group received $100 \%$ oxygen, and the nitrous oxide group received $50 \% \mathrm{~N}_{2} \mathrm{O}$ in oxygen over $2 \mathrm{~min}$. After anesthesia was induced with $2.5 \%$ thiopental sodium $5 \mathrm{mg} / \mathrm{kg}$ and manual occlusion of the forearm was performed, $1 \%$ lidocaine $1 \mathrm{mg} / \mathrm{kg}$ was injected over $15 \mathrm{sec}$. After the occlusion was released, $0.1 \%$ rocuronium $0.6 \mathrm{mg} / \mathrm{kg}$ was injected over 5 sec. Patient response to rocuronium injection was graded using a 4-point scale.

Results: Overall incidence of withdrawal movements was significantly lower in the nitrous oxide group (1 patients; $3.1 \%)$ than in the oxygen group (8 patients; $25.8 \%)(\mathrm{P}=0.013)$. No patient in the nitrous oxide group displayed arm or generalized movement (grade 3 or 4 ) associated with rocuronium injection.

Conclusions: This study demonstrated that a combination of inhaled $50 \% \mathrm{~N}_{2} \mathrm{O}$ in $\mathrm{O}_{2}$ and $1 \mathrm{mg} / \mathrm{kg}$ lidocaine pretreatment significantly reduced the incidence of rocuronium-induced withdrawal movements in pediatric patients compared with lidocaine pretreatment alone. (Korean J Anesthesiol 2010; 58: 446-449)

Key Words: Lidocaine, Nitrous oxide, Rocuronium, Withdrawal.

\section{Introduction}

Pain is a common side-effect reported by $50-80 \%$ of patients receiving rocuronium injection [1-3]. Severe withdrawal movements tend to occur more frequently in pediatric patients, possibly because small veins take longer to clear. It can be a troublesome situation when sudden flexion of wrist and elbow, or other generalized movement occurs during injection of rocuronium. Several methods have been applied in an attempt to decrease the incidence of withdrawal movement in children. These include lidocaine [3], ketamine [4], or opioid $[5,6]$ injection prior to rocuronium injection. These, however, do not completely eliminate withdrawal movement in all cases. Nitrous oxide is a well-established, centrally-acting sedative and analgesic agent. However, use of nitrous oxide to reduce withdrawal movement after rocuronium in children has not

Received: January 7, 2010. Revised: 1st, February 23, 2010; 2nd, March 10, 2010. Accepted: March 15, 2010.

Corresponding author: Jong-Yeop Kim, M.D., Department of Anesthesiology and Pain Medicine, Ajou University School of Medicine, San 5, Woncheon-dong, Paldal-gu, Suwon 442-721, Korea. Tel: 82-31-219-5574, Fax: 82-31-219-5579, E-mail: kjyeop@ajou.ac.kr

(c) This is an open-access article distributed under the terms of the Creative Commons Attribution Non-Commercial License (http:// creativecommons.org/licenses/by-nc/3.0/), which permits unrestricted non-commercial use, distribution, and reproduction in any medium, provided the original work is properly cited. 
been reported. Therefore, this prospective, randomized study evaluated the efficacy of a combination of nitrous oxide and lidocaine pretreatment on the withdrawal response during rocuronium injection in children.

\section{Materials and Methods}

This study was approved by the institutional review board, and informed parental consent was obtained. The study was conducted prospectively on 66 patients between the ages of 5 and 12 years, with ASA physical status I or II, undergoing general anesthesia for elective surgery. Patients with known allergy to local anesthetics, asthma, neurologic deficits, those receiving analgesics or sedatives within the previous 24 hours, or those crying on arrival in the operating room were excluded from this study. Three children were excluded due to crying and one due to failure of IV access. No premedication was administered before surgery. Before arriving at the operating room, a 22 or 24-gauge cannula was inserted in the dorsum of the hand, and its position was confirmed by the free flow of a dextrose/saline infusion by gravity. Upon arrival at the operating room, all patients were monitored with electrocardiogram, pulse oxymeter, non-invasive arterial pressure, and capnography. Patients were randomly assigned to two groups using a computer generated randomization table. Patients in the oxygen group $(n=33)$ were preoxygenated with $100 \%$ oxygen. Patients in the nitrous oxide group $(\mathrm{n}=33)$ were preoxygenated with $50 \% \mathrm{~N}_{2} \mathrm{O}$ mixture in oxygen. The fresh gas flow was set at $6 \mathrm{~L} / \mathrm{min}$. Study gases were administrated with a face mask gently held on the patients' face, but with an effective seal. Patients in both groups were asked to breathe normally via a face mask for 2 min prior to induction. In both groups, anesthesia was induced with $2.5 \%$ thiopental sodium $5 \mathrm{mg} / \mathrm{kg}$ followed by a free flow of IV fluid until loss of consciousness. Thirty seconds later, manual occlusion of the forearm was performed with sufficient force to stop IV flow by gravity, and $1 \%$ lidocaine $1 \mathrm{mg} / \mathrm{kg}$ was injected over $15 \mathrm{sec}$ while manual forearm pressure was maintained, then released, followed by injection of $0.1 \%$ rocuronium $0.6 \mathrm{mg} / \mathrm{kg}$ over $5 \mathrm{sec}$. Assisted

Table 1. Patient Characteristics

\begin{tabular}{lcc}
\hline & $\begin{array}{c}\mathrm{O}_{2} \\
(\mathrm{n}=31)\end{array}$ & $\begin{array}{c}\mathrm{N}_{2} \mathrm{O} \\
(\mathrm{n}=32)\end{array}$ \\
\hline Sex (M/F) & $18 / 13$ & $16 / 16$ \\
Age (yr) & $7.7 \pm 2.3$ & $7.1 \pm 1.7$ \\
Weight (kg) & $26.1 \pm 8.4$ & $26.0 \pm 7.6$ \\
ASA physical status (I/II) (n) & $26 / 5$ & $28 / 4$ \\
Cannula size (22/24-gauge) (n) & $13 / 18$ & $15 / 17$ \\
\hline
\end{tabular}

Values are mean \pm SD or number of patients. No significant differences between the two groups were noted. mask ventilation with $\mathrm{O}_{2}$ (or mixture of $\mathrm{O}_{2}$ and $\mathrm{N}_{2} \mathrm{O}$ ) was applied if desaturation was observed $\left(\mathrm{SpO}_{2}<90 \%\right)$. All medications were injected into a port connected directly to the IV catheter while the IV tubing was clamped above the injection site. After injection of rocuronium, fluids were administrated at a gravity flow. No visible precipitation occurred in the transparent portion of the IV tubing. Patients, anesthesia providers, and investigators who scored the movements were blind to the gas mixture administered to patients (flowmeters were covered by cardboard). Patient response was graded by the investigator according to the scale proposed by Shevchenko et al. [3], as follows: 1 = no response, 2 = movement at the wrist only, $3=$ movement/withdrawal involving arm only (elbow/shoulder), and $4=$ generalized response, movement/withdrawal in more than one extremity. The investigator also recorded the incidence of coughing and breath holding. Once responses were graded, the study was terminated. Anesthesia was continued based on the decision of the anesthetist.

From previous studies [3], rocuronium induced-withdrawal movement after pretreatment with lidocaine was expected to be approximately $45 \%$. Therefore, 30 subjects per group would be needed to decrease this incidence to $10 \%$ (power $80 \%$ and $\alpha=0.05$ ). The sample size was increased to 66 patients on assumption of a $10 \%$ dropout rate. Statistical analyses were performed using the statistical package (SPSS 13.0 for windows, SPSS Inc, Chicago, IL, USA). Data are presented as mean \pm SD or number of patients. Patient characteristics were compared with Student's t-test or Fisher's exact test where appropriate. Incidence of withdrawal movement was analyzed with Fisher's exact test. A P value $<0.05$ was considered significant.

\section{Results}

A total of 66 patients were initially enrolled in the study. One patient in the nitrous oxide group became excited and started crying, and two patients in the oxygen group did not complete the study due to unwillingness to cooperate. Hence, data for 63 patients is presented. No significant difference was observed in patient characteristics between the two groups (Table 1).

Table 2. Incidence and Grade of Withdrawal Movements Associated with Rocuronium Injection

\begin{tabular}{lcc}
\hline Grade of withdrawal movements & $\begin{array}{c}\mathrm{O}_{2} \\
(\mathrm{n}=31)\end{array}$ & $\begin{array}{c}\mathrm{N}_{2} \mathrm{O} \\
(\mathrm{n}=32)\end{array}$ \\
\hline 1 (No withdrawal) & $23(74.1)$ & $31(96.9)^{*}$ \\
2 (Wrist withdrawal) & $2(6.5)$ & $1(3.1)$ \\
3 (Arm only) & $4(12.9)$ & $0(0.0)$ \\
4 (Generalized movement) & $2(6.5)$ & $0(0.0)$ \\
\hline
\end{tabular}

Values are number of patients (percentage). ${ }^{*} \mathrm{P}<0.05$ compared with group $\mathrm{O}_{2}$. 
Incidence and grade of withdrawal movement are listed in Table 2. Overall incidence of withdrawal movements was significantly lower in the nitrous oxide group (1 patients; $3.1 \%$ ) than in the oxygen group ( 8 patients; $25.8 \%)(\mathrm{P}=0.013)$. In the oxygen group, 4 and 2 patients showed arm withdrawal movement (grade 3) and generalized movement (grade 4), respectively. None of the patients in the nitrous oxide group displayed arm or generalized movement (grade 3 or 4 ) associated with rocuronium injection. There were no significant differences in the $\mathrm{SpO}_{2}$ between the two groups, and $\mathrm{SpO}_{2}$ remained above $90 \%$ throughout the study period.

\section{Discussion}

This study demonstrated that a combination of inhaled $50 \%$ $\mathrm{N}_{2} \mathrm{O}$ in $\mathrm{O}_{2}$ mixture and pretreatment of $1 \mathrm{mg} / \mathrm{kg}$ lidocaine significantly reduced the incidence of rocuronium-induced withdrawal movements in pediatric patients compared with lidocaine pretreatment alone.

The need to reduce withdrawal movement or pain during rocuronium injection has encouraged a number of different approaches using local anaesthetics, opioids, sodium bicarbonate and many other drugs [3-10]. Among these, one of the most popular methods is the pretreatment of lidocaine with or without tourniquet technique, as in propofol injection pain [11]. However, even using lidocaine, the incidence of rocuronium induced-withdrawal movements or pain has been reported to between $46 \%$ and $17.5 \%$ [3,7-10]. Incidence of withdrawal movement in our study, following lidocaine pretreatment alone was $25.8 \%$, comparable findings from previous studies. Furthermore, incidence of withdrawal movements decreased to $3.1 \%$, in addition to inhalation of $50 \% \mathrm{~N}_{2} \mathrm{O}$ mixture over $2 \mathrm{~min}$, as well as lidocaine pretreatment. The central antinociceptive effects of nitrous oxide may prevent the pain that results from the local irritant effect of rocuronium [12]. $\mathrm{N}_{2} \mathrm{O}$ has been used as an analgesic and as an anesthesia, and is still widely used today. $\mathrm{N}_{2} \mathrm{O}$ has been reported to affect a variety of different receptors, including opioid [13], noradrenergic [14], acetylcholine [15], $\gamma$-aminobutyric acid (GABA) [16], and $N$-methyl-d-aspartate (NMDA) [17] receptors. However, the mechanisms underlying its unique pharmacodynamic profile have not yet been fully clarified. Moreover, it is believed that the different effects of $\mathrm{N}_{2} \mathrm{O}$ (analgesic, anxiolytic, amnestic, hallucinogenic, and sedative, among others) are mediated by different pathways. Opioid receptors in the periaqueductal gray, noradrenergic descending inhibitory pathways, and inhibitory interneurons in the spinal cord [18] are thought to be involved in the analgesic action of $\mathrm{N}_{2} \mathrm{O}$. Because $\mathrm{N}_{2} \mathrm{O}$-induced analgesic action could be indirectly achieved through mediation by different pathways, exposure time to $\mathrm{N}_{2} \mathrm{O}$ in this study $(<5 \mathrm{~min})$ may be insufficient for production of an adequate analgesic effect. Therefore, further study for elucidation of the analgesic effect of $\mathrm{N}_{2} \mathrm{O}$ might be needed.

On the other hand, the effect of lidocaine was more likely the result of local anesthetic effect at the site of injection, due to the fact that venous occlusion technique was applied to the forearm over $15 \mathrm{sec}$ from time of injection of lidocaine until rocuronium was injected. Therefore, a limited amount of lidocaine injected reached systemic circulation. Ahmad et al. [9] suggested that the central analgesic effect of a drug is only effective if adequate time is allowed for onset of analgesia, whereas pretreatment with drugs having local anesthetic properties is effective when administered immediately before, or with a venous occlusion technique.

A high concentration of $\mathrm{N}_{2} \mathrm{O}$, such as $70 \%$, may cause side effects including excitement, dysphoria, nausea, restlessness and opisthotonic movements [19]. Concentrations of 15$45 \% \mathrm{~N}_{2} \mathrm{O}$ produce quantifiable and meaningful increases in the threshold for both sensation and tolerance of pain. At concentrations below $50 \%$, the analgesic effect of $\mathrm{N}_{2} \mathrm{O}$ follows a linear dose response pattern [20], although cognitive and other psychological factors also have an influence. As a result, we chose to use a concentration of $50 \% \mathrm{~N}_{2} \mathrm{O}$. In addition, we enrolled children older than 5 years because it was our experience that these children could perform tidal volume breath with masks on their faces. $\mathrm{N}_{2} \mathrm{O}$ is widely available, easy to administer, and relatively free of side effects, bringing it to the useful analgesic agent in pediatric patients. Nevertheless, in our study, one patient in the nitrous oxide group developed side effects that included excitement and crying. Although the effect of $\mathrm{N}_{2} \mathrm{O}$ can be quickly reversed by stopping the $\mathrm{N}_{2} \mathrm{O}$, and the complication of inhaled $\mathrm{N}_{2} \mathrm{O}$ may be brief and benign, the possibility of this complication occurring with the use of $\mathrm{N}_{2} \mathrm{O}$ must be considered. Another potential concern with the use of $\mathrm{N}_{2} \mathrm{O}$ during induction would be unanticipated difficult airway and compromised preoxygenation. Although, previous study has found that preoxygenation with mixtures of oxygen and $\mathrm{N}_{2} \mathrm{O}$ can help to smooth induction without impairment of oxygenation [21], care should be taken for possible desaturation during anesthetic induction in children.

In conclusion, pretreatment of two different analgesic modalities, nitrous oxide and lidocaine, prevents withdrawal movement grade 3 and 4 (arm only and generalized movement) associated with rocuronium injection, and reduces overall incidence of withdrawal movement in children.

\section{References}

1. Steegers MA, Robertson EN. Pain on injection of rocuronium bromide. Anesth Analg 1996; 83: 203. 
2. Borgeat A, Kwiatkowski D. Spontaneous movements associated with rocuronium: is pain on injection the cause? Br J Anaesth 1997; 79: 382-3.

3. Shevchenko Y, Jocson JC, McRae VA, Stayer SA, Schwartz RE, Rehman M, et al. The use of lidocaine for preventing the withdrawal associated with the injection of rocuronium in children and adolescents. Anesth Analg 1999; 88: 746-8.

4. Liou JT, Hsu JC, Liu FC, Ching-Wah Sum D, Lui PW. Pretreatment with small-dose ketamine reduces withdrawal movements associated with injection of rocuronium in pediatric patients. Anesth Analg 2003; 97: 1294-7.

5. Kim JY, Kim JY, Kim YB, Kwak HJ. Pretreatment with remifentanil to prevent withdrawal after rocuronium in children. Br J Anaesth 2007; 98: 120-3.

6. Oh AY, Seo KS, Goo EK, Park YO, Kim SJ, Kim JH. Prevention of withdrawal movement associated with injection of rocuronium in children: comparison of remifentanil, alfentanil and fentanyl. Acta Anaesthesiol Scand 2007; 51: 1190-3.

7. Memis D, Turan A, Karamanlioglu B, Sut N, Pamukcu Z. The prevention of pain from injection of rocuronium by ondansetron, lidocaine, tramadol, and fentanyl. Anesth Analg 2002; 94: 1517-20.

8. Turan A, Memis D, Karamanlioglu B, Sut N, Pamukcu Z. The prevention of pain from injection of rocuronium by magnesium sulphate, lignocaine, sodium bicarbonate and alfentanil. Anaesth Intensive Care 2003; 31: 277-81.

9. Ahmad N, Choy CY, Aris EA, Balan S. Preventing the withdrawal response associated with rocuronium injection: a comparison of fentanyl with lidocaine. Anesth Analg 2005; 100: 987-90.

10. Yavascaoglu B, Kaya FN, Ozcan B. Esmolol pretreatment reduces the frequency and severity of pain on injection of rocuronium. J Clin Anesth 2007; 19: 413-7.
11. Picard P, Tramér MR. Prevention of pain on injection with propofol: a quantitative systematic review. Anesth Analg 2000; 90: 963-9.

12. Gillman MA, Lichtigfeld FJ. Clinical role and mechanisms of action of analgesic nitrous oxide. Int J Neurosci 1998; 93: 55-62.

13. Fujinaga M. Mechanisms of nitrous oxide-induced analgesic effects. Int Congr Ser 2005; 1283: 132-6.

14. Sawamura S, Kingery WS, Davies MF, Agashe GS, Clark JD, Kobilka $\mathrm{BK}$, et al. Antinociceptive action of nitrous oxide is mediated by stimulation of noradrenergic neurons in the brainstem and activation of $\alpha 2$-B adrenoceptors. J Neurosci 2000; 20: 9242-51.

15. Yamakura T, Harris RA. Effects of gaseous anesthetics nitrous oxide and xenon on ligand-gated ion channels. Comparison with isoflurane and ethanol. Anesthesiology 2000; 93: 1095-101.

16. Hapfelmeier G, Zieglgansberger W, Haseneder R, Schneck H, Kochs E. Nitrous oxide and xenon increase the efficacy of GABA at recombinant mammalian GABAA receptors. Anesth Analg 2000; 91: 1542-9.

17. Mennerick S, Jevtovic-Todorovic V, Todorovic SM, Shen W, Olney JW, Zorumski CF. Effect of nitrous oxide on excitatory and inhibitory synaptic transmission in hippocampal cultures. J Neurosci 1998; 18: 9716-26.

18. Maze M, Fujinaga M. Pharmacology of nitrous oxide. Best Pract Res Clin Anaesthesiol 2001; 15: 339-48.

19. Henderson JM, Spence DG, Komocar LM, Bonn GE, Stenstrom RJ. Administration of nitrous oxide to pediatric patients provides analgesia for venous cannulation. Anesthesiology 1990; 72: 269-71.

20. Benedetti C, Chapman CR, Colpitts YH, Chen AC. Effects of nitrous oxide concentration on event-related potentials during painful tooth stimulation. Anesthesiology 1982; 56: 360-4.

21. Khoo ST, Woo M, Kumar A. Preoxygenation techniques: the value of nitrous oxide. Acta Anaesthesiol Scand 1993; 37: 23-5. 